\title{
AN AVOCADO MONSTROSITY
}

\author{
ROBERT W. HODGSON \\ University of California, Berkeley, Cal.
}

W

ITH the rapid extension of avocado planting in California and the consequent demand for trees, nurserymen have had occasion to raise many thousands of seedlings. during the last four or five years. Among such a large number naturally some abnormal forms have appeared such as albinos and dwarfs, and among others a few teratological monstrosities have been reported. The latter usually take the form of fasciation in which terminal nodes have become expanded, presenting a ridged, flat stern of greatly increased width upon which normal buds are borne. Among such peculiar forms none more striking has been reported than that pictured in Fig. 7 which was found in a lot of Grande seedlings in the University greenhouse. This particular case does not exhibit the usual characteristics of fasciation and seems worthy of being put on record.

The pectliar growth was first noticed when the seedling was about seven months old and is still present. Although the first leaves were shed some time ago, the new growth exhibits the same peculiarity. The malformation consists of the hypertrophy of the terminal cluster of leaves together with several adjacent nodes. The leaves are markedly modified both in form, size, and consistency. The size is greatly reduced, and the terminal node is so shortened that the leaves are crowded together much as in the case of a brussels sprout. The consistency and form of the leaves are so modified that the general appearance is that of a much corrugated, imbricated mass of white fleshy tissue possessing a shiny surface.

Very careful examination revealed no traces of the presence of insects or of wounds caused by them. Microscopical examination has failed to show any indication of fungi. The general appear- ance of the modified leaves suggested a possible connection between them and the large fleshy cotyledons, but study has failed to confirm this. The cotyledon tissue was found to contain very large quantities of starch, some sugar, and notable amounts of oil. The abnormal tissue contained little of these but was fairly rich in protein. The cells of the cotyledon tissue were found to be heavy walled, larger, and in other ways distinctly different from the spongy pith-like, thin walled tissue of the modified leaves. Sections through such leaves showed that they lacked the palisade layer and spongy parenchyma entirely and possessed but a rudimentary vascular system. A few cells containing chloroplastids were found scattcred here and there.

The effect of the abnormality on the growth of the seedling has been such that a shoot from a node further down has developed and has taken the ascendency. This fact together with the fact that all subsequent growth of the affected nodes has been of the abnormal type seems to indicate that the stimulus or change resulting in the peculiar growth has probably not been of a momentary nature such as the sting of an insect. To be sure, it may be possible that the abnormal tissue in this case is analagous to new forms which have been produced by the injection of certain chemicals into the ovaries of plants as established by Lloyd and MacDougal, but in this case the change has been purely somatic.

Examination of the literature does not discover much that is helpful in classifying this peculiarity and indicates that our present knowledge as to the cause of teratological forms is quite unsatisfactory. Thorough study of such forms might help unravel the mystery concerning the causes leading up to bud-mutations. 


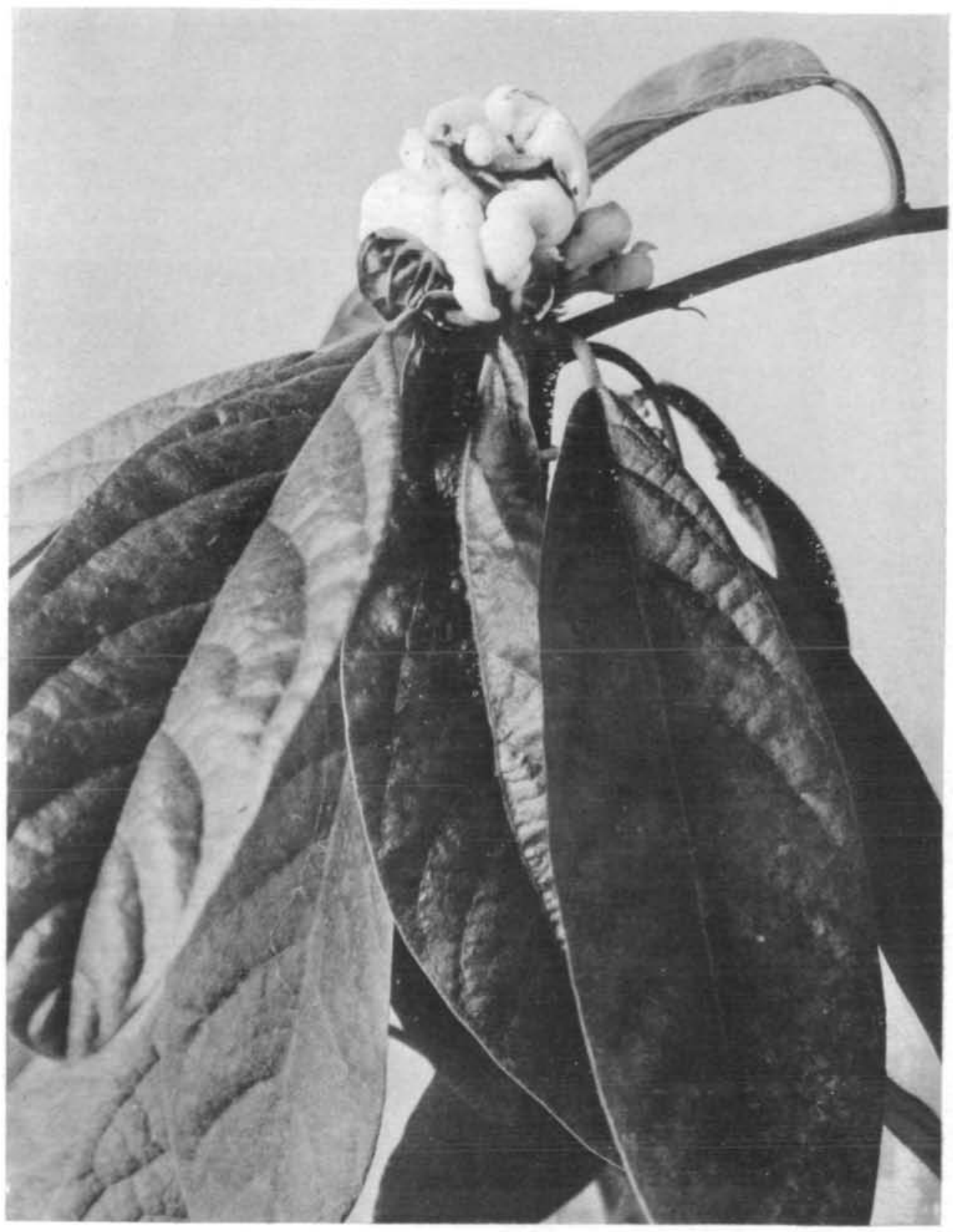

PECULIAR GROWTH ON AVOCADO SEEDLING

This peculiar growth appeared on a Grande seedling seven months after planting. All the subsequent growth of the infected nodes has been of the same nature. No traces of insect injury or fungus parasites have been found. What has caused this change? May it not be of the same nature which results in a bud-mutation? (Fig. 7.) 